\title{
Empirical Capacity Measurements of Electric Vehicles Subject to Battery Degradation from V2G Service
}

Thingvad, Andreas; Calearo, Lisa; Andersen, Peter Bach; Marinelli, Mattia

Published in:

IEEE Transactions on Vehicular Technology

Link to article, DOI:

10.1109/TVT.2021.3093161

Publication date:

2021

Document Version

Peer reviewed version

Link back to DTU Orbit

Citation $(A P A)$ :

Thingvad, A., Calearo, L., Andersen, P. B., \& Marinelli, M. (2021). Empirical Capacity Measurements of Electric Vehicles Subject to Battery Degradation from V2G Service. IEEE Transactions on Vehicular Technology, 70(8), 7547 - 7557. https://doi.org/10.1109/TVT.2021.3093161

\section{General rights}

Copyright and moral rights for the publications made accessible in the public portal are retained by the authors and/or other copyright owners and it is a condition of accessing publications that users recognise and abide by the legal requirements associated with these rights.

- Users may download and print one copy of any publication from the public portal for the purpose of private study or research.

- You may not further distribute the material or use it for any profit-making activity or commercial gain

- You may freely distribute the URL identifying the publication in the public portal 


\title{
Empirical Capacity Measurements of Electric Vehicles Subject to Battery Degradation from V2G Services
}

\author{
Andreas Thingvad, Student Member, IEEE, Lisa Calearo, Student Member, IEEE, \\ Peter Bach Andersen, Member, IEEE, Mattia Marinelli, Senior Member, IEEE
}

\begin{abstract}
Accelerated battery degradation, resulting in a reduced capacity, is the main concern when discussing vehicle-to-grid (V2G) services. This paper gives a unique empirical insight into the long-term effects on batteries performing an energy demanding V2G service. To this end, an extensive method for measuring the battery capacity of series produced electric vehicles $(\mathrm{EVs})$ via the DC charge port was developed. The reproducibility of the method is demonstrated with repeated tests on new and aged vehicles and the results are compared with the EVs internal estimates, read via the on-board diagnostics port. The method is also validated with a state-of-the-art battery degradation model. The capacity test method is used to evaluate the battery degradation of a fleet of commercially owned EVs which, as a part of the world's first commercial operation, have been used for V2G services for five years. The EVs have, together with $\pm 10 \mathrm{~kW}$ V2G chargers, been delivering primary frequency regulation for 15 hours per day with a daily energy throughput of $50.6 \mathrm{kWh}$. The usable battery capacity, initially found to be $23 \mathrm{kWh}$, after two years is reduced on average to $20.7 \mathrm{kWh}$ and after five years is reduced to 18.9 kWh.
\end{abstract}

Index Terms-Ancillary Services, Battery degradation, Electric Vehicles, Frequency Control, Vehicle-to-Grid

\section{INTRODUCTION}

Due to the electrification of the transportation sector, the number of electric vehicles (EVs) is expected to increase exponentially in the coming years. Controlling the charging makes it possible for the EVs to minimise their energy cost and for the power system to achieve multiple operational objectives simultaneously [1]. The use of EVs for providing ancillary services to the power system can be an additional revenue for EV owners and can assist the integration of larger amounts of renewable sources [2].

The frequency-controlled normal operation reserve (FCR-N) is a type of primary frequency regulation in the North European power system. It is a symmetric service requiring equal amount of power for up and down regulation of frequency deviations of up to $100 \mathrm{mHz}$ [3]. It has been experimentally shown in [4] that EVs can deliver FCR-N by charging at $11 \mathrm{~A}$ with a regulating capacity of $\pm 1.15 \mathrm{~kW}$ ( 5 A@230 V), giving a range of $1.4-3.7 \mathrm{~kW}(6-16 \mathrm{~A})$. The

Copyright (c) 2015 IEEE. Personal use of this material is permitted. However, permission to use this material for any other purposes must be obtained from the IEEE by sending a request to pubs-permissions@ieee.org.

The work in this paper has been supported by the research projects ACES (EUDP grant nr: EUDP17-I-12499) and ACDC (EUDP grant nr. 64019-0541). Website: www.aces-bornholm.eu www.acdc-bornholm.eu

The authors are from Center for Electric Power and Energy, Department of Electrical Engineering. DTU - Technical University of Denmark, Roskilde, Denmark. Email: \{athing,lica,pba,matm\}@elektro.dtu.dk limiting factor is the amount of time the EV can consume power, before being fully charged. A daily driving distance of $45 \mathrm{~km} /$ day, with a corresponding energy consumption of 9 $\mathrm{kWh}$ results in three hours of service provision per day and a yearly capacity payment of $€ 52[5]$. The time limitation can be avoided by using a bidirectional vehicle-to-grid (V2G) charger. The symmetry can be created by correspondingly charging or discharging during over and under frequency periods, and thereby use the EV battery as a buffer rather than just a flexible load. Using bidirectional chargers significantly increases the revenue, but also the conversion losses in the charger and the energy throughput of the battery [6]. An EV that delivers FCR-N every night for 15 hours with a $\pm 10 \mathrm{~kW}$ V2G charger can earn a yearly capacity payment of $€ 1100$, but it is found to involve an increased energy throughput of $12 \mathrm{MWh}$ per year, as discussed in Ref. [5], that could prematurely wear the battery.

Battery degradation, resulting in a lower energy capacity, is the main concern when discussing V2G [7]. The reduction in energy capacity, described by the state of health $(\mathrm{SOH})$, is an additional cost that has to be subtracted from the profit of the delivered grid services. If the degradation dynamics decreasing the $\mathrm{SOH}$ are known, they can be included in an optimisation problem when scheduling the charging and service provision [8]. It is however not simple to measure or accurately estimate the SOH of EVs. In fact, the capacity of batteries that are employed as a power source in an EV cannot be measured online [9]. Since an EV never experiences a full charge cycle during normal operation, commercial battery management systems (BMS) estimate the $\mathrm{SOH}$ by comparing the change in state of charge (SOC), according to the change of the open circuit voltage (OCV), to the change in SOC, according to coulomb counting [10]. In Ref. [11], different degradation indicators are extracted from the voltage and electric current variation during charging and discharging. Similar to the BMS method, the SOH can be more accurately estimated based on either the decrease in discharge capacity of discharges with equal voltage drop or charge capacity of charges with equal voltage rise. The accurate $\mathrm{SOH}$ estimation is important to ensure the safety, reliability, and maintenance of the battery system, but accuracy is the biggest bottleneck for most estimation methods [12]. When estimating the $\mathrm{SOH}$ based on partial charges, the accuracy is proportional to the depth of the charge/discharge cycle [10]. A full charge cycle corresponds to measuring the real $\mathrm{SOH}$, which is the approach of the method proposed in the present manuscript. This is the conventional way of measuring the capacity of 
battery cells, but the method has, to the best of the authors knowledge, not before been used via the DC charge port on the pack level of non-disassembled EVs. Thus, avoiding violating the warranty of the vehicle. The BMS in an EV has limited computational power, which constraints the use of computationally heavy methods such as Kalman filters, neural networks, or fuzzy logic to calculate the degradation parameters of the Li-ion battery [13]. A more computationally light, measurement-based method is the incremental capacity analysis (ICA) [14]. With ICA the derivative of the capacity with respect to the derivative of the voltage is plotted as a function of the voltage [15]. As the battery experiences degradation, the peaks of the (IC,V) curve will change. It can then be compared to other IC analysed cells with known $\mathrm{SOH}$, and thereby the $\mathrm{SOH}$ of the battery can be derived [16]. The bottleneck of the ICA is that empirical lifetime analysis for a reference of a certain battery type would require years of studying, which is impractical and would generate reliable results only when the battery has aged [17]. The ICA method is conventionally used on battery cells, however it needs to be feasible on pack or EV level and not only on individual cell level. Nickel Manganese Cobalt (NMC) based cells for the BMW i3 EV has been tested both on cell level and on car level and the results shows consistent characteristic peaks and valleys of the ICA on car and cell level [16, 18].

The simplest capacity models are based on equivalent circuit models (ECM), where the battery is represented by its Thevenin equivalent [19]. A first order ECM of a full EV battery pack is experimentally validated in [20]. In [9], it is found that a second order ECM gives the best compromise between accurate $\mathrm{SOH}$ estimations and low computational demand. Alternatively, more complex single particle models can be used to model the electro-chemical degradation process, which can potentially capture how the cell ages under varying degradation modes, such as lithium consumption at the solid-electrolyte interface or active material dissolution [21].

The factors influencing battery degradation, measured as capacity fade, can be divided in two: calendar ageing, which is a function of time and cycle ageing, which is a function of the number of charge/discharge cycles. Lithium-ion batteries are naturally an unstable structure, which degrade and lose capacity when ageing, despite not being used [22]. Like most chemical reactions, the capacity loss will occur mostly in the beginning and then decreases over time as less of the materials have active interactions. The degradation mechanism occurs faster when there is a high energy density in the battery, which means that it increases with high SOC and temperature [23]. Ref. [22] finds that the battery degradation is twice as high if the battery is stored fully charged than stored at a SOC lower than $60 \%$. To maximise battery life, lithium-ion cells should not be stored at high SOC, and for long-term storage the SOC should be less than $50 \%$ [24]. Ref. [25] shows that active ageing management can extend the life of the EV by avoiding high SOC, when user behaviour allows it. Especially for EV applications, calendar ageing is the dominating effect, because EVs are generally idle more than $90 \%$ of the time. However, economic cost calculations to date have mostly focused on the number of charge/discharge cycles as the determining factor of lifetime [17]. For the active usage of the battery, recent research has shown that increased energy throughput of the battery is causing lithium plating on the anode and mechanical failure, resulting in a capacity loss [17, 26]. Ref. [27] experimentally finds that depending on the temperature, there is a $2-3 \%$ capacity loss per 1000 full equivalent cycles (FEC). Li-ion batteries can be used in vehicular applications until they have lost $20-30 \%$ of the initial capacity, but can at this point still be used in second life applications as stationary storage until $50 \%$ of the capacity is lost [28].

The contributions of the present manuscript are twofold:

1) An empirical method for measuring the battery capacity of series produced EVs via the DC charge port.

2) Capacity measurements of ten EVs that have delivered V2G services with a large energy throughput for five years. The measured battery degradation is compared with the simulated results obtained with an industrial battery model.

The remaining paper is organised as follows: Section II describes the main parameters used when modelling the battery degradation of EVs. Section III describes the empirical method for measuring the battery capacity of EVs. Section IV describes the use case of ten EVs that have delivered FCR-N in Denmark for five years, and presents the measured energy throughput of the battery. Section $\mathrm{V}$ presents the results of repeated tests of new and aged vehicles to determine the initial capacity as well as the reproducibility of the method. The simulated capacity loss for the use case and the measurements of the ten EVs over a period of three years are presented. Finally section $\mathrm{VI}$ presents the conclusions of the study and the future work.

\section{BATTERY DEGRADATION THEORY}

The authors cooperated with Nissan Motors Research Center in modelling the effect of FCR-N provision on the battery degradation in Denmark [29]. The model dynamics are described in [30] for a $40 \mathrm{kWh}$ battery, experimentally validated in [20]. Whereas in this article a similar representative $24 \mathrm{kWh} \mathrm{EV}$, with battery characteristics modelled as Lithium Nickel Manganese Cobalt Oxide batteries is taken as reference. The model is run with a simulation step of $1 \mathrm{~s}$, thereby capturing the effect of the short term power flows on the battery temperature. Each second the battery temperature, SOC, throughput and $\mathrm{SOH}$ are calculated. The $\mathrm{SOH}$ is found from the two components of the capacity loss in percent of the original capacity: calendar ageing, $\mathrm{L}_{\text {cal }}$ and cycle degradation $\mathrm{L}_{\text {cyc }}$. The total capacity loss is the sum of the two components and the $\mathrm{SOH}$ is calculated with Eq. (1).

$$
\mathrm{SOH}=100 \%-\mathrm{L}_{\mathrm{cal}}-\mathrm{L}_{\mathrm{cyc}}
$$

\section{A. Calendar Ageing}

The capacity loss due to calendar ageing can be found with the Arrhenius equation shown in Eq. (2), which describes the temperature dependence of reaction rates. The pre-exponential factor $\mathrm{f}$ shown in Eq. (2) is according to [31] fitted with a 
TABLE I: Coefficient values and units

\begin{tabular}{lll}
\hline $\mathrm{a}$ & $8.581 \cdot 10^{-6}$ & $1 /\left(\mathrm{K}^{2} \cdot \mathrm{Ah}\right)$ \\
$\mathrm{b}$ & $-5.102 \cdot 10^{-3}$ & $1 /(\mathrm{K} \cdot \mathrm{Ah})$ \\
$\mathrm{c}$ & 0.7589 & $1 / \mathrm{Ah}$ \\
$\mathrm{d}$ & $-6.7 \cdot 10^{-3}$ & $1 / \mathrm{K}$-(C-rate) \\
$\mathrm{e}$ & 2.344 & $1 /(\mathrm{C}-$ rate $)$ \\
$\mathrm{f}$ & 1.5 & Ah/Cycle \\
\hline
\end{tabular}

piece-wise linear function of the SOC as shown in Eq. (3). The parameters are the absolute battery temperature in kelvin, $\mathrm{T}$, the activation energy for the reaction, $\mathrm{E}_{\mathrm{a}}=24.5 \mathrm{~kJ} \mathrm{~mol}^{-1}$, the universal gas constant, $\mathrm{R}=8.314 \mathrm{~J} \mathrm{~mol}^{-1} \mathrm{~K}^{-1}$ and the age of the battery in days, $\mathrm{d}$.

$$
\begin{gathered}
\mathrm{L}_{\mathrm{cal}}(\mathrm{d})[\%]=f(\mathrm{SOC}) \cdot \exp \left(-\frac{\mathrm{E}_{\mathrm{a}}}{\mathrm{R} \cdot \mathrm{T}}\right) \cdot \sqrt{\mathrm{d}} \\
f(x)= \begin{cases}-1.04 \cdot x^{2}+89.72 \cdot x+1224.6 & \text { if } x \leq 50 \\
10.35 \cdot x^{2}-1083.6 \cdot x+31447 & \text { if } 50 \leq x<70 \\
2.64 \cdot x^{2}-409.55 \cdot x+22035 & \text { if } 70 \leq x\end{cases}
\end{gathered}
$$

The relationship between capacity loss $\mathrm{L}_{\mathrm{cal}}$ per $\sqrt{\mathrm{d}}$, the SOC and the temperature of the battery is shown for different temperatures in Fig. 1. A battery stored at $60 \% \mathrm{SOC}$ and $20^{\circ} \mathrm{C}$ will, after the first year have lost $0.16 \cdot \sqrt{365}=3.1 \%$ and after five years have lost $0.16 \cdot \sqrt{365 \cdot 5}=6.8 \%$ capacity due to calendar ageing.

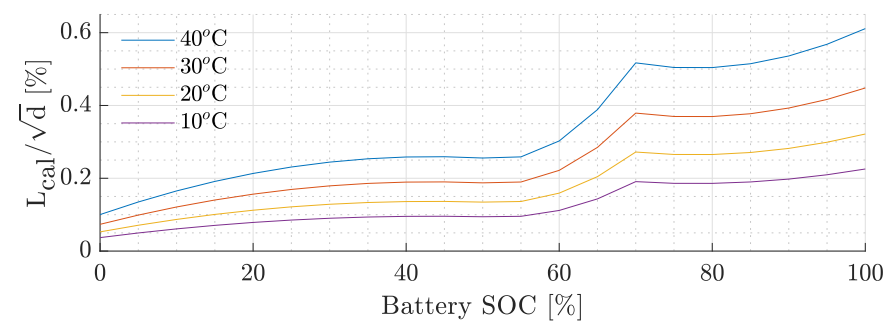

Fig. 1: Capacity loss due to calendar ageing per $\sqrt{\mathrm{d}}$ when stored at different temperatures and SOC.

\section{B. Cycle Degradation}

The cycle degradation is the capacity loss caused by the active use described by the number of FECs. $\mathrm{L}_{\mathrm{cyc}}$ is temperature dependent, thus it is calculated based on the throughput of each second at the specific battery temperature, $\mathrm{T}$, at that time. The temperature dependence of the $\mathrm{L}_{\mathrm{cyc}}$ is empirically found per $\mathrm{Ah}$ in [27] for a $1.5 \mathrm{Ah}$ cell and is normalised by multiplying with $1.5 \mathrm{Ah} /$ cycle in [29]. In Eq. (4), the $\mathrm{L}_{\mathrm{cyc}}$ per FEC is shown. The $\mathrm{C}$-rate describes the rate that a battery is being discharged or charged. It is defined as the current through the battery, divided by the nominal capacity in Ah. The degradation per FEC is higher, when C-rate is above 1.

$$
\mathrm{L}_{\mathrm{cyc}}[\%]=\left(\mathrm{a} \cdot \mathrm{T}^{2}+\mathrm{b} \cdot \mathrm{T}+\mathrm{c}\right) \cdot \exp ((\mathrm{d} \cdot \mathrm{T}+\mathrm{e}) \cdot \mathrm{C}-\mathrm{rate}) \cdot \mathrm{f} \cdot \mathrm{N}_{\mathrm{FEC}}
$$

The coefficient of Eq. (4) are shown in table [1 The capacity loss per FEC at different battery temperatures is plotted as function of the battery temperature in Fig. 2

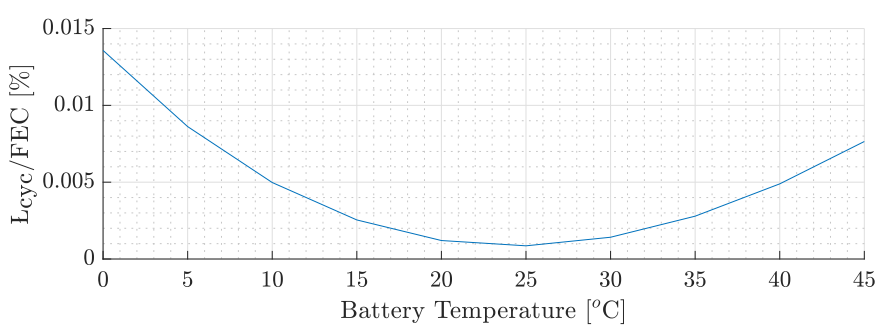

Fig. 2: Capacity loss per FEC at different battery temperatures

\section{Measurement Method}

This section defines in subsection $A$ how to measure the $\mathrm{SOH}$ of individual battery cells, followed by subsection $B$ which presents how the $\mathrm{SOH}$ can be measured when the cells are arranged in an EV battery pack. This is followed by a description of the internal sensor readings and estimates of the EV BMS that can be read out and compared with the external measurements in subsection $C$. In subsection $D$, the measurement layout of the capacity test and how to measure the power of the battery, the self-consumption during charging and how to calculate the total battery capacity of the EV are presented. In subsection $E$, it is described how the $\mathrm{EV}$ can be discharged to the minimum SOC, before starting the charging process that will determine the capacity. Subsection $F$ shows how the full charge consists of a constant current and a constant voltage phase before the EV reaches 100\% SOC. Finally, subsection $G$ describes how the measured data can also be used for ICA, which results are presented in section $\mathrm{V}$

\section{A. State of Health of Battery Cells}

The SOH refers to the full energy capacity of the battery relatively to the initial capacity. It decreases due to irreversible degradation mechanisms and is defined in Eq. (5), as the full capacity of the cell, $Q_{\text {full }}$, in percent of the initial capacity, Qinit [32]:

$$
S O H=\frac{\mathrm{Q}_{\text {full }}}{\mathrm{Q}_{\text {init }}}
$$

The $\mathrm{SOH}$ of individual Li-ion cells is conventionally found by measuring the capacity during full charge and discharge cycles. Generally, the discharge capacity is of main interest compared to the charge capacity, as it shows the usable capacity. The difference between the two values is only caused by the internal losses and these can be made negligible by charging with a low C-rate.

For a time resolution of $\mathrm{t}_{\mathrm{s}}=1 \mathrm{~s}$ and $\Delta \mathrm{T}=3600 \mathrm{~s} / \mathrm{h}$, the full capacity in Wh can be calculated by integrating the product of the voltage, $\mathrm{V}_{k}$, and the current, $\mathrm{I}_{k}$ as in Eq. (6). The duration of the full charge in seconds, $\mathrm{N}_{\text {test }}$, is a function of the physical battery capacity and charge power. It is the time it takes to charge the battery from empty to full capacity.

$$
\mathrm{Q}_{\text {full }}=\frac{1}{\Delta \mathrm{T}} \sum_{k=1}^{\mathrm{N}_{\text {test }}} \mathrm{I}_{k} \cdot \mathrm{V}_{k} \cdot \mathrm{t}_{\mathrm{s}}
$$




\section{B. State of Health of EV Battery Packs}

For EV applications it is only possible to measure the battery capacity during charging and not discharging. Due to the internal resistance, the terminal voltage is larger than the OCV during charging and lower during discharging. The difference between the capacity for charging and discharging will therefore increase when the internal resistance increases due to ageing. The difference between the charging and discharging capacity can be reduced by charging with a low power. An EV battery pack has a number of battery cells connected in series, and the voltage measured at the pack terminals is the sum of the voltage of all the cells. All the cells in series experience the same current, which means that they are discharged with the same amount of Ah. Due to production inaccuracies and different temperatures in the battery pack, the $\mathrm{SOH}$ is not the same for all the cells. It is therefore the role of the BMS to balance the SOC of the individual cells. If initially all cells are balanced at $100 \%$ SOC, the battery can be discharged until the cell with the lowest capacity reaches the minimum voltage and limits the pack. The usable capacity for discharge is equal to the capacity of the smallest cell in the string, multiplied with the number of cells in series $\mathrm{N}_{\text {cells. }}$. When charging the EV, the BMS performs passive balancing, where energy is drawn from the most charged cell and dissipated as heat through parallel resistors. The balancing results in all the cells reaching $100 \%$ SOC. The consumption during a full charge is the energy needed for bringing the smallest cell to $100 \%$ plus the energy needed for balancing the individual cells.

\section{CAN-bus Information}

In all series produced cars, most internal information is communicated on the open Central Area Network (CAN)-bus, which can be accessed via the on-board diagnostic port (OBDII). A CAN-bus scanner connected to the OBDII plug that communicates over bluetooth with a smartphone can be used. For Nissan EVs a third party app called LeafSpy is used to interpret the data [33]. The voltage of the individual cells, the estimated SOC, the value of the battery temperature sensors and the BMS own estimation of the $\mathrm{SOH}$ can be read from the CAN-bus.

Fig. 3 shows the CAN-bus information collected before and after a full charge of a $24 \mathrm{kWh}$ Nissan e-NV200. Fig. 3a shows the status of the EV before the start of the charge and Fig. $3 \mathrm{~b}$ shows the status at the end of the charge. The BMS deactivates the supply to the auxiliary battery when the lowest cell voltage reaches a certain threshold. As the battery cells are series connected, the imbalance of the cells make some of the capacity inaccessible. The value $264 \mathrm{mV}$ in Fig. 3a shows the voltage difference between the highest and lowest cell voltage. After the charge, the balancing process reduced the voltage gap to $17 \mathrm{mV}$. According to the CAN-bus reading, the BMS does not charge to $100 \%$, even though the dashboard displays "SOC $=100 \% "$ to the driver. This indicates that the internal SOC value is calculated from the energy capacity relative to the initial capacity, but in all cases it is higher than the " $\mathrm{SOH}$ " value, also seen in Fig. 3 The EV in Fig. $3 b$ is charged to

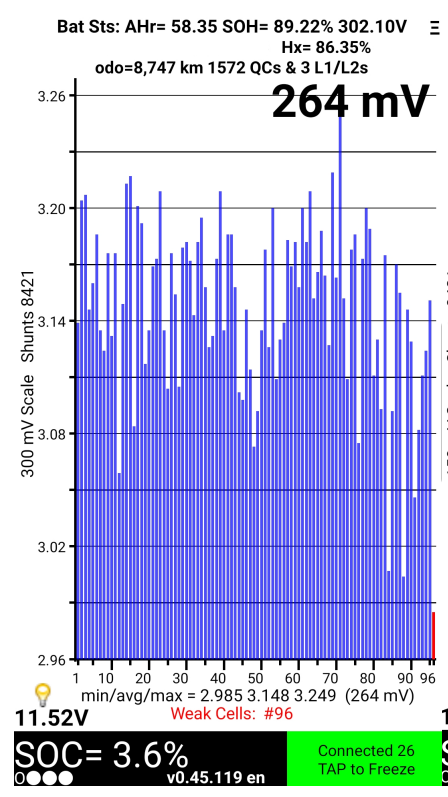

(a) Before full charge.

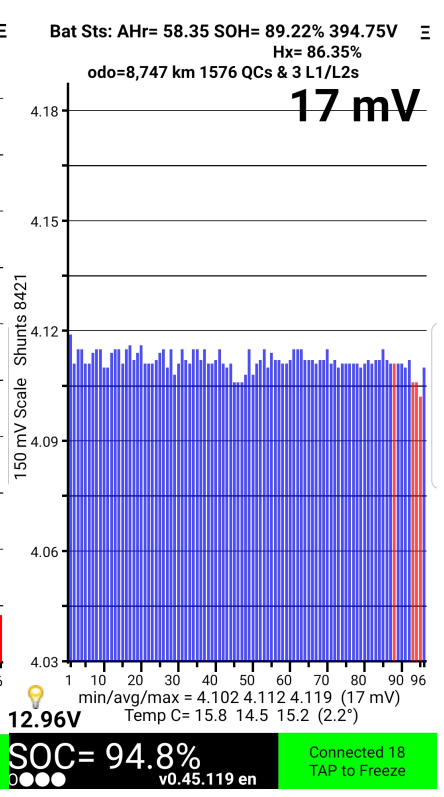

(b) After full charge.
Fig. 3: Screenshot of the LEAFspy app, reading from CAN-bus via a bluetooth OBDII adapter. Before and after charge test FF02-02.

$394.75 \mathrm{~V}$ on the pack level, or to an average of $4.11 \mathrm{~V}$ for each cell, highest achieved voltage considered to correspond to the maximum SOC.

\section{Measurement Layout}

Most EV models can charge with AC using the on-board charger or with an external DC charger that connects directly to the battery terminals, as shown in Fig. 4 .

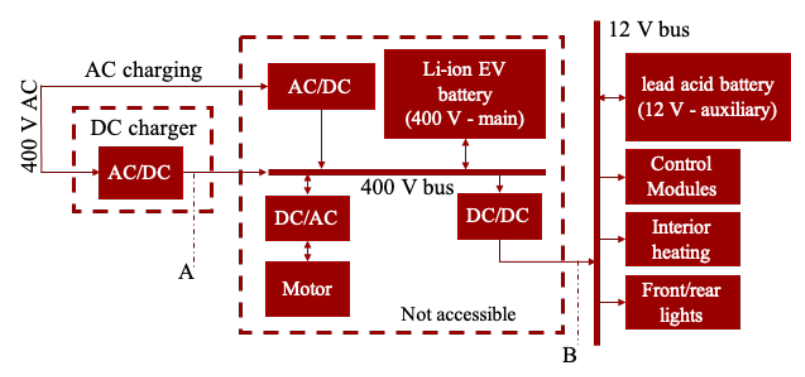

Fig. 4: Overview of EV power flows. Battery capacity measured at point A and point $\mathrm{B}$.

When charging with the on-board charger the battery voltage and current are not accessible, which means that the charged energy can only be measured on the AC side of the converter. This is however not equal to the energy received by the battery as the on-board charger of several brands have been found to have an efficiency of $90 \%$ [34]. Therefore, it is necessary to use an external charger, where the DC voltage and current can be measured directly at the terminals of the battery. The DC voltage and current are measured inside the charger at the charging cable connected to the EV, shown as point A in Fig. 4 The BMS has a power consumption during the charging process, which is measured and subtracted from the 
energy received from the charger, to find the energy capacity of the main battery. All of the auxiliary consumption during charging is on the $12 \mathrm{~V}$ bus where the voltage and current from the main battery is measured at point B in Fig. 4 It is assumed that the DC/DC converter supplying the low voltage bus has $100 \%$ efficiency, so the battery capacity can be calculated as follows:

$$
\mathrm{Q}_{\text {full }}=\frac{1}{\Delta \mathrm{T}} \sum_{k=1}^{\mathrm{N}_{\text {test }}}\left(\mathrm{I}_{k}^{\mathrm{A}} \cdot \mathrm{V}_{k}^{\mathrm{A}}-\mathrm{I}_{k}^{\mathrm{B}} \cdot \mathrm{V}_{k}^{\mathrm{B}}\right) \cdot \mathrm{t}_{\mathrm{s}}
$$

In point $A$, the current is measured with a current clamp (Prosys CP30) that generates a DC voltage of $100 \mathrm{mV} / \mathrm{A}$ with an accuracy of $\pm 1 \%$, and the battery voltage is measured using a voltage differential probe (Hioki P9000-01) that divides the voltage with 100 and outputs a voltage between $0-5 \mathrm{~V}$, with an accuracy of $\pm 0.5 \%$, see Fig. 5 . In point B, the auxiliary battery voltage is directly measured, and the current flowing from the main to the $12 \mathrm{~V}$ battery is measured with a current clamp (Prosys CP1005) giving $10 \mathrm{mV} / \mathrm{A}$ with $\pm 1 \%$ accuracy. The voltages are measured through galvanically separated channels with a Hioki LR8431 data-logger, with an accuracy of $\pm 0.1 \%$ full scale (f.s. $10 \mathrm{~V}$ for voltage and current in point $\mathrm{A}, 1 \mathrm{~V}$ and $20 \mathrm{~V}$ current and for voltage in point $\mathrm{B}$ ), and logged with 1 second resolution on a USB stick. The DC power in point $\mathrm{A}$ is the product of the voltage and current with an accuracy of $1+0.5+0.3+0.2=2 \%$. In point $\mathrm{B}$, the accuracy is $0.1+1+0.2=1.3 \%$ but, since the amount of energy is $15 \%$ of the energy in point $\mathrm{A}$, it is a small contribution to the overall result. Therefore it can be safely considered that the total accuracy of the measurements is $2.3 \%$.

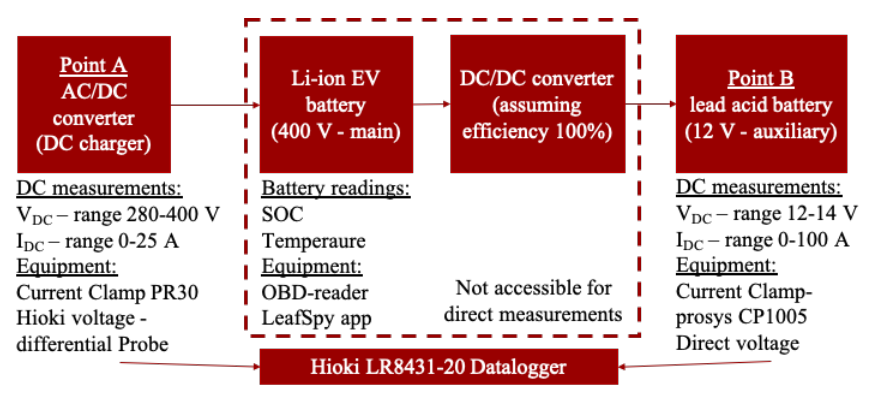

Fig. 5: Measuring points and equipment used

\section{E. Discharging Process}

Before the charge capacity test, the EV should be as discharged as possible, in order to measure the maximum battery capacity. The discharging process is not measured. The tested EVs can be discharged to a minimum of $6 \%$ SOC, displayed by the Leaf Spy, by driving and heating, at which point the power supply for the drive train and cabin heating system is turned off. The front lights are then used to further discharge the battery until the battery reaches approx. $3 \%$ SOC, at which point the supply from the main to the auxiliary battery is discontinued. This event can be detected by a drop in the auxiliary battery voltage from $14 \mathrm{~V}$ to $12 \mathrm{~V}$.

\section{F. Charging Process}

The battery is charged via the external DC charger through the CHAdeMO connector. In Fig. 6, it is shown the pack terminal voltage and current measured in point $\mathrm{A}$, during a full charge of a $24 \mathrm{kWh}$ Nissan e-NV200. It can be seen that the constant current phase is two hours, followed by one hour of charging with constant voltage.

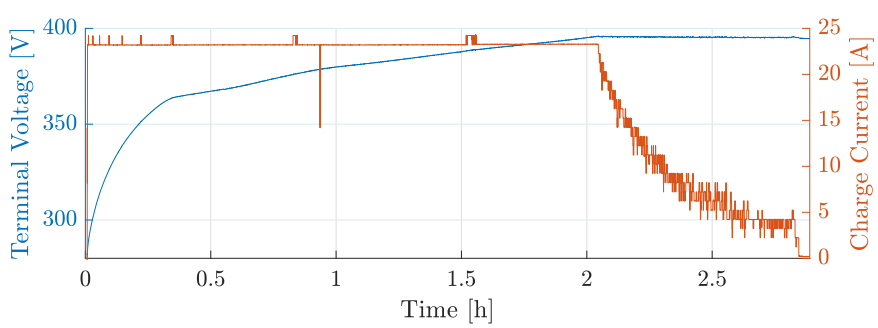

Fig. 6: Voltage (left axis) and current (right axis) measured at the EV battery terminals during a full charge of a $24 \mathrm{kWh}$ Nissan e-NV200 EV. Measured at point A (Fig. 4 .

Fig. 7 shows the power flow from the main to the auxiliary battery during the charging process. The supply from the main to the auxiliary battery is for this EV around $8 \mathrm{~A}$ at $14 \mathrm{~V}$, resulting in a consumption of approximately $100 \mathrm{~W}$. There is a higher power flow in the beginning of the charge, as the auxiliary battery is initially fully recharged. The auxiliary consumption during a full charge is for a Nissan e-NV200 around $300 \mathrm{Wh}$. The capacity measurement method has been tested on different Nissan models; Nissan e-NV200 (24 kWh) and Nissan LEAF $(24,30$ and $40 \mathrm{kWh})$.

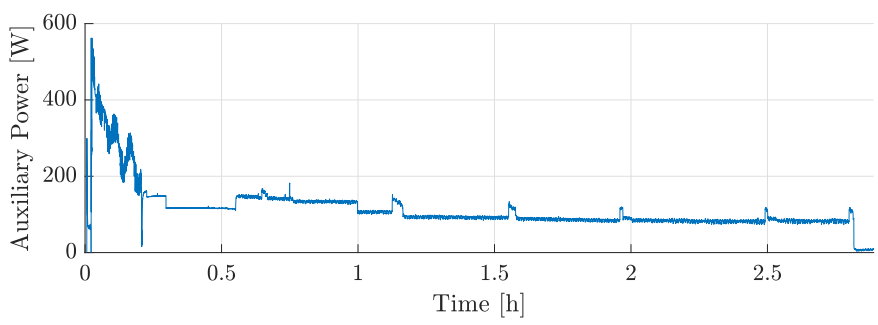

Fig. 7: Power flow from the main battery to the auxiliary battery during a full charge of a $24 \mathrm{kWh}$ Nissan e-NV200 EV. Measured at point B (Fig. 4 .

\section{G. Incremental Capacity Analysis}

The ICA method has been applied on the battery pack level. The Incremental Capacity (IC) is defined as the Ah charge differentiated with respect to the voltage. The derivative of the charged Ah capacity, $\mathrm{Q}_{\mathrm{Ah}}$, with respect to the derivative of the voltage, $\mathrm{v}$, is plotted as a function of the voltage, so the location of the tops and valleys can be compared for cells with different $\mathrm{SOH}$. The IC is defined in Eq. [8] [15].

$$
\mathrm{IC}=\frac{d \mathrm{Q}_{\mathrm{Ah}}}{d \mathrm{v}}[\mathrm{Ah} / \mathrm{V}]
$$

The change in voltage has been kept fixed at $0.3 \mathrm{~V}$ and the corresponding change in capacity in Ah is then calculated for the number of seconds, $\mathrm{N}_{\mathrm{s}}$, the voltage increase took over. The 
capacity is defined as the integration of the charging current as in Eq. (9).

$$
\mathrm{Q}_{\mathrm{Ah}}=\frac{1}{\Delta \mathrm{T}} \sum_{k=1}^{\mathrm{N}_{\mathrm{s}}} \mathrm{I}_{k} \cdot \mathrm{t}_{\mathrm{s}}
$$

In order to avoid noise in the the IC, the voltage and current have been through a moving average filter with a duration of $300 \mathrm{~s}$ before Eq. (8) has been applied [16]. The IC calculation is only considered during the constant current charging mode, in order to avoid variation of the voltage due to the internal resistance of the battery.

\section{EleCtric Vehicle USE CASE}

The Danish research project, Parker, has demonstrated that commercially owned EV fleets together with V2G chargers can be used to commercially deliver FCR-N [35]. As part of a commercial pilot demonstration connected to the Parker project, a fleet of ten Nissan e-NV200 electric vans, owned by the utility company Frederiksberg Forsyning (FF), has been delivering FCR-N since the end of 2016. The e-NV200, which has a nameplate capacity of $24 \mathrm{kWh}$ is designed for commercial operation with regular fast charging, so unlike other Nissan EVs it has active battery cooling during charging. The ten FF EVs were purchased at the same time, registered in Denmark on 07/07/2016 and produced 3 months before. The capacity of all ten FF e-NV200 have been measured six times over the last three years for this study.

The EVs are used by FF during the working hours, and for FCR-N during the night and full time in the weekend. Looking at the ten EVs as a group, they are in $99 \%$ of the workdays plugged in latest at 18:00 and plugged out earliest at 06:30, giving a 12.5 hour daily connection period [36].

In the following, each EV at FF is numbered 1-10 with the prefix FF (FF01, FF02 etc.). Each charger record data for one specific EV and its user [37]. Data from the V2G chargers at FF is logged every second and the analysed period considered is 480 days from November 2016 to March 2018. The data includes the energy capacity of the battery in $\mathrm{kWh}$ and the battery voltage and current measured by the charger.

\section{A. Energy Throughput from FCR-N and Driving}

Based on the charger data, the average time the charger has an active power flow for either regular charging or FCR-N is calculated. The average number of active hours per day, $\mathrm{N}_{t}$ [h], is provided in Table II]. The throughput is calculated as the sum of all ampere or watt going in and out of the battery. For a time resolution of $\mathrm{t}_{\mathrm{s}}=1 \mathrm{~s}$ and $\Delta T=3600 \mathrm{~s} / \mathrm{h}$ the throughput in $\mathrm{Ah}, \mathrm{Ah}_{\mathrm{tp}}$, and $\mathrm{Wh}, \mathrm{E}_{\mathrm{tp}}$, is calculated as the sum of the absolute current in Eq. (10) and the sum of the absolute current times the voltage in Eq. [11, divided by the number of days in the sample period, $\mathrm{N}_{\mathrm{SP}}$, which is 480 .

$$
\begin{gathered}
\mathrm{Ah}_{\mathrm{tp}}=\frac{1}{\Delta \mathrm{T} \cdot \mathrm{N}_{\mathrm{SP}}} \sum_{k=1}^{\mathrm{N}_{\text {test }}}\left|\mathrm{I}_{k}\right| \cdot \mathrm{t}_{\mathrm{S}} \\
\mathrm{E}_{\mathrm{tp}}=\frac{1}{\Delta \mathrm{T} \cdot \mathrm{N}_{\mathrm{SP}}} \sum_{k=1}^{\mathrm{N}_{\text {test }}}\left|\mathrm{I}_{k}\right| \cdot \mathrm{V}_{k} \cdot \mathrm{t}_{\mathrm{S}}
\end{gathered}
$$

The daily measured throughput for the period is shown in Table [I] for each of the ten EVs from November 2016 to March 2018.

The throughput measured by the charger contains both the flow caused by the FCR-N service and the charging to cover the driving consumption. The throughput during driving is not measured, but it is estimated based on the drop in the SOC while the EV is plugged out. The average consumption for driving is only $5 \mathrm{kWh}$ per day [36]. Knowing the driven distance from the vehicle odometer throughout the entire considered period, the average distance driven per day $\left(\mathrm{N}_{\text {odo }}\right)$ in $\mathrm{km}$ is derived for each vehicle and provided in Table II

TABLE II: Average daily values for: duration of daily active power $\left(\mathrm{N}_{t}[\mathrm{~h}]\right)$, throughput $\left(\mathrm{E}_{\mathrm{tp}}[\mathrm{kWh}], \mathrm{Ah}_{\mathrm{tp}}[\mathrm{Ah}]\right)$, driving distance $\left(\mathrm{N}_{\mathrm{odo}}[\mathrm{km}]\right)$ and fraction of missing data $\left(e_{\text {data }}[\%]\right)$ for each of the ten EVs from November 2016 to March 2018 (480 days).

\begin{tabular}{c|cccccccccc} 
& FF01 & FF02 & FF03 & FF04 & FF05 & FF06 & FF07 & FF08 & FF09 & FF10 \\
\hline $\mathrm{N}_{\mathrm{t}}$ & 15.5 & 15.7 & 13.5 & 15.9 & 14.1 & 14.6 & 14.1 & 9.4 & 12.1 & 14.4 \\
$\mathrm{Ah}_{\mathrm{tp}}$ & 112.5 & 118.8 & 97.9 & 120.8 & 112.5 & 116.7 & 108.3 & 89.6 & 89.6 & 106.3 \\
$\mathrm{E}_{\mathrm{tp}}$ & 43.8 & 47.9 & 37.5 & 47.9 & 41.7 & 45.8 & 43.8 & 33.3 & 35.4 & 41.7 \\
$\mathrm{~N}_{\text {odo }}$ & 9.6 & 5.8 & 6.0 & 7.9 & 5.6 & 10.4 & 5.0 & 4.1 & 3.6 & 8.3 \\
$\mathrm{e}_{\text {data }}$ & $2 \%$ & $4 \%$ & $12 \%$ & $2 \%$ & $5 \%$ & $5 \%$ & $10 \%$ & $39 \%$ & $11 \%$ & $9 \%$
\end{tabular}

The average driving distance for the ten vehicles is 7 $\mathrm{km} /$ day. Due to server or charger errors, some data is not collected, which explains most of the difference between the result of the individual cars. The fraction of data missing, $\mathrm{e}_{\text {data }}$, is significantly higher for FF08, as shown in the last row of table [I] The plug-in time during the workdays are 12.5 hours but since the EVs are used for FCR-N 24 hours per day in the weekend and holidays, the average time with an active power flow is 15 hours per day, when correcting for the lost error data.

The measured average throughput of the ten EVs is 41.9 $\mathrm{kWh}$ per day, but when correcting for the lost data, the average is $45.6 \mathrm{kWh}$ to which the average driving consumption of 5 $\mathrm{kWh}$ is added, resulting in a total throughput of $50.6 \mathrm{kWh}$ per day. This can be divided with two times the battery capacity, $\mathrm{Q}_{\text {full }}$, to find the corresponding full equivalent charge/discharge cycles of the battery as in Eq. [12.

$$
\mathrm{N}_{\mathrm{FEC}}=\frac{\mathrm{E}_{\mathrm{tp}}}{2 \mathrm{Q}_{\mathrm{full}}}
$$

A capacity of $24 \mathrm{kWh}$ results in 1.05 full charge/discharge cycles per day, but a repeated throughput gives an increasing number of cycles as the battery capacity decreases over time.

Since the second-based charger data measurements are not available for the entire lifetime, the throughput in $\mathrm{kWh}$ is compared and validated with a smart meter installed at the beginning of 2019 by the distribution system operator for billing purposes. The smart meter was installed the $7^{\text {th }}$ of January 2019 and the values were read the $30^{\text {th }}$ of April 2021, showing the import and export for all the vehicles for 844 days. The total electricity import for the 844 days was 247 MWh and the total export was $128 \mathrm{MWh}$. The consumption for driving and conversion losses is found by subtracting the import and export, whereas the throughput is the sum of the two. The daily average throughput measured by the billing meter from January 2019 to end of April 2021 is $44.6 \mathrm{kWh}$ per vehicle per day to which the average driving consumption 
of $5 \mathrm{kWh}$ is added, resulting in a total throughput of $49.6 \mathrm{kWh}$ per day. The energy consumption for losses and driving is 14.0 $\mathrm{kWh}$ per vehicle per day. By subtracting the average driving consumption of $5 \mathrm{kWh}$, the remaining energy for losses is $9.0 \mathrm{kWh}$ per vehicle per day. The consumption for conversion losses of $9.0 \mathrm{kWh}$ per day corresponds to $3.3 \mathrm{MWh}$ per year. The average energy throughput measured by the DSO meter during the most recent 2.3 year is almost the same as what is measured by the chargers (when correcting for the missing data) during the first 1.3 year. It is assumed that the daily energy throughput has been in the range of $49.6-50.6 \mathrm{kWh}$ for the whole period.

\section{RESUlTS}

The result section contains six subsections. In the first one repeated tests of a new $24 \mathrm{kWh}$ EV are presented to determine the initial battery capacity. The second subsection reports results on some of the aged vehicles that have been tested multiple times to validate the reproducibility of the method, comparing the measurements with the data collected from the CAN-bus. The third subsection presents the predicted $\mathrm{SOH}$ according to the degradation model. The fourth subsection presents the measured $\mathrm{SOH}$ and the SOH according to the BMS, which are compared with the predicted $\mathrm{SOH}$ according to the model. The fifth subsection presents the ICA of every charge test for two of the vehicles. The final subsection discusses the economic implications of the accelerated degradation caused by increased energy throughput.

\section{A. Initial Battery Capacity of Nissan e-NV200}

In order to determine the initial usable battery capacity of the Nissan e-NV200, since a completely new EV was not available, a one year old Nissan e-NV200 Evalia was considered. The Evalia was registered in Denmark 28-06-2017 and the capacity was measured on the 28-08-2018, when the odometer was only $700 \mathrm{~km}$ and the model was rarely used for V2G experiments in the DTU lab. The usable battery capacity of this model is then used as the base case for calculating the $\mathrm{SOH}$. The Evalia was measured three times with a capacity of $22.7,23.2$ and $23.0 \mathrm{kWh}$. The average capacity of 23 $\mathrm{kWh}$ is a conservative number, representing a new vehicle as the measurements are based on a one-year old EV. This is however the only empirical result and the remaining paper uses $\mathrm{Q}_{\text {init }}=23.0 \mathrm{kWh}$, for this generation of EVs with a nameplate capacity of $24 \mathrm{kWh}$. The EV uses cells with a nominal voltage of $3.85 \mathrm{~V}$ and a nominal capacity of 32.7 Ah. Nominal voltage and capacity are not publicly available and thus derived by the authors, the nominal voltage as the average OCV measured during the constant current phase of the full charge, and the nominal capacity retrieved with the LeafSpy. Since the pack consists of 96 cells in series and 2 cells in parallel, the nominal capacity is $24.2 \mathrm{kWh}$.

\section{B. Method Reproducibility Validation}

To determine the validity of the method when measuring the capacity of more degraded cars, the capacity measurements of some of the FF EVs were repeated. The capacity of FF10 was measured four times and the capacity test of FF07 and FF02 were repeated once. The measured results are shown in Table III together with the relevant information read from the CAN-bus. The measured capacity in $\mathrm{kWh}$ is calculated with Eq. (7). The measured $\mathrm{SOH}$ is based on the measured capacity divided with the initial capacity of $23 \mathrm{kWh}$, as in Eq. (5). The initial voltage is the voltage measured at the battery terminals before the charge. The initial SOC, the final SOC and the $\mathrm{SOH}$ according to the BMS is read from the CAN-bus together with the initial and final battery temperature. The N/A are due to data acquisition errors.

TABLE III: Comparison of measurement results and the CAN-bus reading of repeated tests of FF10 (tested 21/09/2018), FF07 (tested 07/06/2019) and FF02 (tested 29/05/2020).

\begin{tabular}{c|ccc|cc|c|cc} 
& \multicolumn{4}{|c|}{ Measured values } & \multicolumn{5}{c}{ CAN-bus reading } \\
\hline & Cap. & SOH & Init V & \multicolumn{2}{c}{ SOC [\%] } & \multicolumn{2}{c}{ SOH } & \multicolumn{2}{c}{ Batt. T [C [C $^{0}$} \\
Test & {$[\mathrm{kWh}]$} & {$[\%]$} & {$[\mathrm{V}]$} & Init & End & {$[\%]$} & Init & End \\
\hline FF10-1 & 20.4 & 88.6 & 309.1 & 3.8 & 94.7 & 91.8 & 23.7 & 15.6 \\
FF10-2 & 20.6 & 89.6 & 305.4 & 3.4 & 94.3 & 91.7 & 26.8 & 14.9 \\
FF10-3 & 20.5 & 89.0 & 292.4 & 3.4 & N/A & 91.9 & 26.3 & N/A \\
FF10-4 & 20.5 & 89.0 & 298.7 & 4.3 & 94.5 & 92.3 & 20.2 & 15.5 \\
\hline FF07-1 & 20.7 & 90.2 & 290.0 & 2.5 & 92.0 & 90.0 & 36.6 & 19.6 \\
FF07-2 & 20.8 & 90.5 & 299.0 & 3.5 & 95.2 & 90.0 & 26.6 & 15.7 \\
\hline FF02-1 & 19.6 & 85.3 & 302.6 & 3.6 & 94.8 & 89.2 & 16.6 & 14.8 \\
FF02-2 & 19.9 & 86.7 & 291.5 & 3.6 & 94.8 & 89.2 & 16.6 & 15.5
\end{tabular}

The results of the repeated capacity tests differ of maximum $1 \%$ for FF10 and FF07 and $1.4 \%$ for FF02. Another measurable quantity is the initial battery voltage, which being related to the SOC, shows the minimum level the battery was discharged to. The minimum voltage differs from test to test, as the cell imbalance is slightly different each time. A high minimum pack voltage is an indication that the battery is degraded, because the cell imbalance increases when individual cells degrade more than others. During the first test, FF02-1 initial voltage was $302.6 \mathrm{~V}$, while for the second test it was $291.5 \mathrm{~V}$. During the second test the voltage increased quickly in the beginning, and after 46 seconds and $83 \mathrm{Wh}$ the battery reached $302.6 \mathrm{~V}$. The difference of the minimum pack voltage therefore has a limited effect on the measured battery capacity. The difference of the minimum voltage is uncorrelated to the variations of the minimum SOC (according to the BMS) read from the CAN-bus. According to the CAN-bus reading, the battery stops the supply around $3 \%$ SOC, when limited by the lowest cell voltage. This limit varies between tests, and the BMS stops the discharge when the lowest cell voltage reaches a level between $2.8-3.1 \mathrm{~V}$.

It is not possible to measure the internal battery temperature directly, but the BMS has three sensors located in the battery pack that can be read from the CAN-bus. Table III provides the average value of the three sensors, at the beginning and at the end of the charging process. The initial temperature is significantly higher if the EV has been discharged by driving, compared to the slower stationary discharge via the auxiliary system. However the difference in initial temperature does not appear to have an effect on the measured capacity, which could be explained by the battery being cooled down to $15^{\circ} \mathrm{C}$ at the end of the charge. The two tests of FF02 had the largest difference in initial temperature $36.6^{\circ} \mathrm{C}$ and $26.2^{\circ} \mathrm{C}$, but the 
measured capacity was almost the same, with $20.7 \mathrm{kWh}$ for the warm test and $20.8 \mathrm{kWh}$ for the cold.

The capacity measurement method is expected to be applicable for all car brands that can be charged with DC via an external charger. Nevertheless, complications in understanding the results can occur in case, for certain car models, the BMS makes more battery capacity available over time. This aspect could be detected by a change in the minimum or maximum voltage.

\section{Model Simulation Results}

In this subsection the model results from [29] are presented. The model that has been built in a collaboration with the Nissan Research Center is based on the theory provided in Section III The model results are compared with the measurements, both from our empirical methodology and from the CAN-bus. The input to the model is described in [29]. The $24 \mathrm{kWh} \mathrm{EV}$, such as the ones used at FF, is subject to a year of measured outside air temperature in Denmark and providing FCR-N with $\pm 10 \mathrm{~kW} \mathrm{V2G}$ chargers when grid connected. A representative 14-hour sample of the frequency measured every second in Denmark is in the simulation repeated every day for five years. The frequency sample is used to calculate the power response of the EV according to the grid code which resulted in a daily energy throughput of $38.9 \mathrm{kWh}$. The model includes a daily driving consumption of $6.2 \mathrm{kWh}$ followed by a $6.2 \mathrm{kWh}$ of charging, so the total throughput is $51.3 \mathrm{kWh}$, corresponding to a 1.07 FEC per day. In [29], the given air temperature and power profile result in an average $0.0021 \%$ capacity loss per FEC during FCR-N provision.

Table IV shows the result of the industrial battery model. For each year it is shown how much capacity loss the battery experiences due to calendar ageing and cycle degradation. It can be seen that for this application the calendar ageing is the major factor, but that the contribution decreases with time and mostly occurs in the first year. The capacity loss due to the active usage is lower, but it is increasing as the capacity is decreasing. After five years, the $\mathrm{SOH}$ is reduced with $15.73 \%$ where two thirds of the capacity loss is due to calendar ageing and one third is due to the cycling ageing.

In Fig. 8, it is shown how the $\mathrm{SOH}$ evolves over time due to the isolated parts and the total degradation. It can be seen that the $\mathrm{SOH}$ decreases faster in summer than in winter, which is caused by the influence of the outside air temperature.

TABLE IV: Capacity loss due to cycle degradation and calendar ageing as well as the total capacity loss; both per year and accumulated in the first 5 years of the EV life time.

\begin{tabular}{c|ccc|ccc} 
Year & Cal & Cycle & Total & ECal & ECycle & $\sum$ Total \\
\hline 1 & $4.51 \%$ & $0.81 \%$ & $5.32 \%$ & $4.51 \%$ & $0.81 \%$ & $5.32 \%$ \\
2 & $1.97 \%$ & $0.88 \%$ & $2.85 \%$ & $6.48 \%$ & $1.69 \%$ & $8.17 \%$ \\
3 & $1.58 \%$ & $0.96 \%$ & $2.54 \%$ & $8.06 \%$ & $2.66 \%$ & $10.72 \%$ \\
4 & $1.40 \%$ & $1.05 \%$ & $2.45 \%$ & $9.46 \%$ & $3.71 \%$ & $13.17 \%$ \\
5 & $1.37 \%$ & $1.18 \%$ & $2.55 \%$ & $10.83 \%$ & $4.89 \%$ & $15.73 \%$
\end{tabular}

\section{Capacity Measurements}

The charge capacity of the ten EVs at FF was measured six times over three years: September 2018, June 2019, October

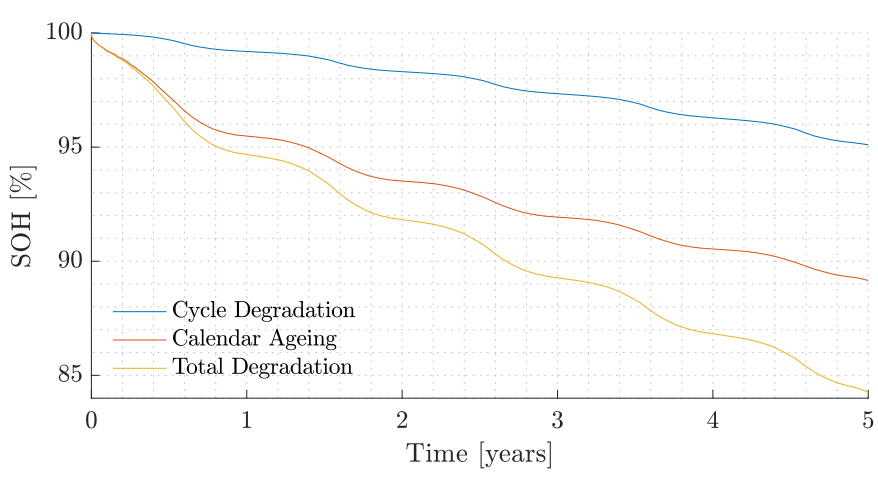

Fig. 8: Modelled SOH of a $24 \mathrm{kWh}$ EV, with 14 hours of FCR-N provision and one hour of charging resulting in 1.07 FEC per day.

2019, May 2020, November 2020 and May 2021. The ten FF EVs were driven to the lab at Technical University of Denmark for capacity testing, as seen in Fig. 9 .

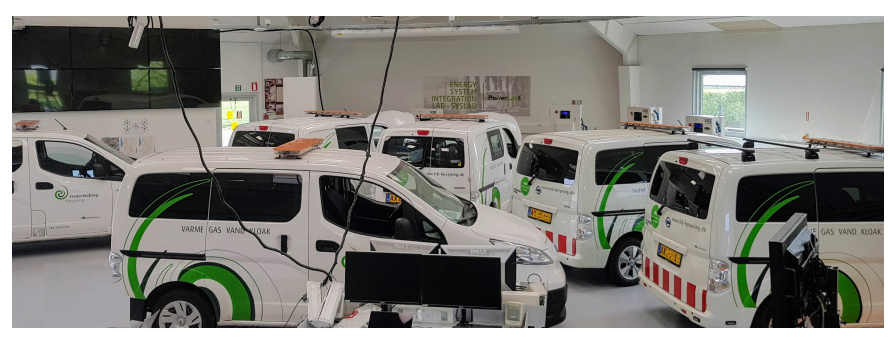

Fig. 9: Capacity measurements at Technical University of Denmark - DTU Risø Campus.

For each capacity test the measured $\mathrm{SOH}, S O H_{\text {meas }}$, is shown in Table $\mathrm{V}$. In parenthesis the $\mathrm{SOH}$ read from the CAN-bus $\left(S O H_{\text {can }}\right)$ is also provided. The N/A in the table is due to data acquisition errors.

The first two measurement sets were carried out at the university laboratory, which means that most of the discharging was done while driving $20 \mathrm{~km}$ from FF to DTU Campus. The last four test rounds were performed at FF with the discharging done stationary via the auxiliary loads. Therefore, some of the EVs had higher initial temperatures in the first tests, which can be seen in Table VI, where the initial, $T_{\text {init }}$, and end, $T_{\text {end }}$, temperatures are given for each charge test (the end temperature in parenthesis). The reported temperatures are the average of the three temperature sensor values.

TABLE V: $S O H_{\text {meas }}$ and $\left(S O H_{\text {can }}\right)[\%]$ of the $10 \mathrm{EVs}$ at FF

\begin{tabular}{|l|l|l|l|l|l|} 
Sep. 2018 & June 2019 & Oct. 2019 & May 2020 & Nov. 2020 & May 2021 \\
\hline
\end{tabular} \begin{tabular}{l|l|l|l|l|l|l}
\hline FF01 & $89.2(91.0)$ & $88.0(88.6)$ & $84.5(87.6)$ & $85.3(87.5)$ & $83.6(87.8)$ & $82.7(86.9)$
\end{tabular} \begin{tabular}{l|l|l|l|l|l|l|l} 
FF02 & $90.0(93.1)$ & $91.2(90.7)$ & $84.4(90.2)$ & $85.3(89.2)$ & $81.6(88.6)$ & $81.7(88.6)$
\end{tabular} \begin{tabular}{l|l|l|l|l|l|l|l|l} 
FF03 & 89.7(93.0) & $90.6(90.1)$ & $N / A(90.3)$ & $84.3(90.3)$ & $84.5(89.1)$ & $82.7(88.8)$
\end{tabular}

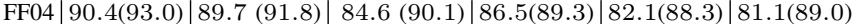

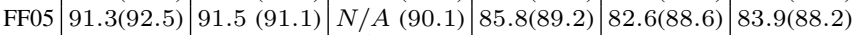
\begin{tabular}{l|l|l|l|l|l|l} 
FF06 & $90.8(93.1)$ & $90.0(91.6)$ & $N / A(90.8)$ & $87.5(90.5)$ & $75.3(89.0)$ & $82.5(89.2)$
\end{tabular} \begin{tabular}{l|l|l|l|l|l|l|l} 
FF07 & $89.1(92.0)$ & $90.2(90.0)$ & $84.3(89.8)$ & $84.6(89.2)$ & $81.4(87.9)$ & $81.8(88.3)$
\end{tabular}

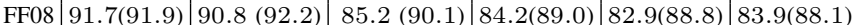
\begin{tabular}{l|l|l|l|l|l|l|l|l} 
FF09 & $91.1(91.5)$ & $86.7(90.3)$ & $N A(89.0)$ & $87.0(88.2)$ & $81.9(87.4)$ & $81.4(87.0)$
\end{tabular} \begin{tabular}{l|l|l|l|l|l|l|} 
FF10 & $88.6(91.8)$ & $85.4(91.3)$ & $84.4(89.8)$ & $84.5(89.3)$ & $81.7(89.0)$ & $80.7(85.3)$
\end{tabular}

In Fig. 10, the $S O H_{\text {meas }}$ is plotted against the age of the $\mathrm{EV}$ in years, together with the modelled $\mathrm{SOH}$ affected by the total degradation (calendar and cycling). The modelled $\mathrm{SOH}$ 
TABLE VI: Average battery temperature at the start $T_{\text {init }}$ and end $\left(T_{\text {end }}\right)$ of the charge, for the $10 \mathrm{EVs}$ at FF

\begin{tabular}{l|r|r|r|r|r|r} 
& Sep. 2018 & June 2019 & Oct. 2019 & May 2020 & Nov. 2020 & May 2021 \\
\hline FF01 & $28.5(16.3)$ & $24.3(15.4)$ & $15.2(15.7)$ & $19.7(15.0)$ & $17.8(15.2)$ & $15.2(15.7)$ \\
FF02 & $24.2(N / A)$ & $35.6(15.2)$ & $15.1(15.6)$ & $16.6(14.8)$ & $9.1(14.9)$ & $9.9(16.5)$ \\
FF03 & $24.4(14.7)$ & $28.6(16.7)$ & $N / A(N / A)$ & $18.4(15.7)$ & $15.0(N / A)$ & $13.8(12.1)$ \\
FF04 & $25.9(16.1)$ & $37.9(18.3)$ & $15.2(15.7)$ & $16.6(14.6)$ & $9.7(15.3)$ & $14.6(15.8)$ \\
FF05 & $27.1(15.9)$ & $32.6(17.1)$ & $N / A(N / A)$ & $18.0(15.3)$ & $8.0(N / A)$ & $10.0(16.8)$ \\
FF06 & $29.4(15.8)$ & $29.8(16.6)$ & $N / A(N / A)$ & $23.4(16.0)$ & $8.1(N / A)$ & $14.5(15.2)$ \\
FF07 & $21.9(14.9)$ & $36.6(19.6)$ & $18.5(14.9)$ & $22.5(15.5)$ & $8.3(14.6)$ & $17.2(16.0)$ \\
FF08 & $25.7(15.3)$ & $25.2(19.2)$ & $15.1(15.3)$ & $18.4(15.0)$ & $13.8(18.0)$ & $17.7(15.5)$ \\
FF09 & $23.9(15.0)$ & $N / A(15.6)$ & $N / A(N / A)$ & $21.7(15.6)$ & $8.6(14.8)$ & $15.0(15.3)$ \\
FF10 & $23.7(15.6)$ & $23.8(19.2)$ & $15.5(15.6)$ & $19.1(15.6)$ & $12.6(N / A)$ & $12.8(11.8)$
\end{tabular}

matches the trend of the capacity measurements, but for most of the EVs the measured degradation is worse.

The $S O H_{\text {can }}$ is also plotted against the EV age, together with the modelled SOH in Fig. 11 . The $S O H_{\text {can }}$ follows the modelled results but generally is above the line.

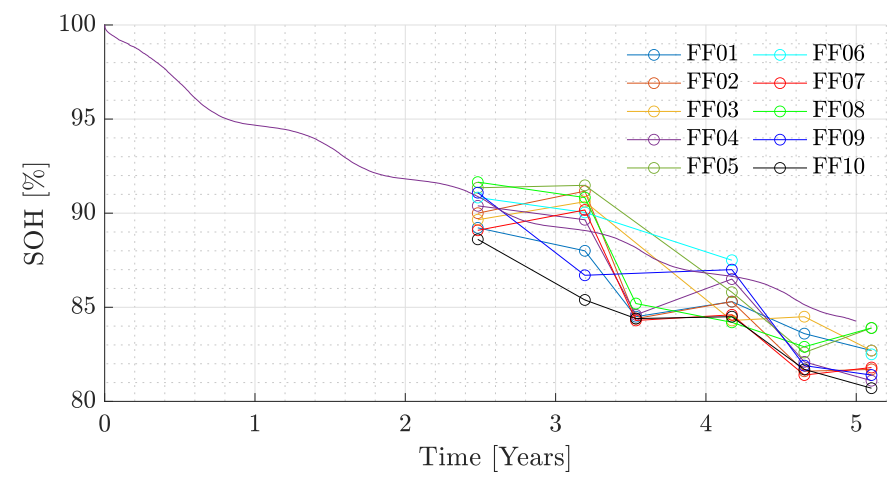

Fig. 10: Comparison of measured $\mathrm{SOH}, \mathrm{SOH}_{\text {meas }}$, with the $\mathrm{SOH}$ model output.

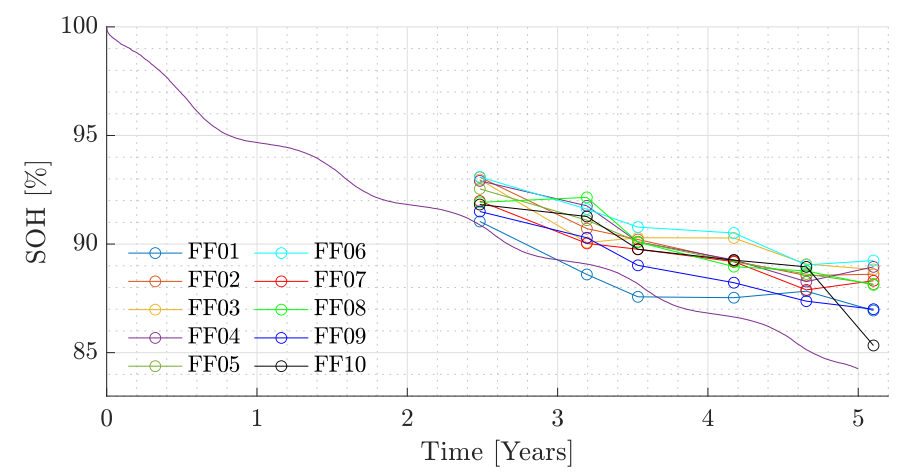

Fig. 11: Comparison of $\mathrm{SOH}$ reading from EV CAN-bus, $\mathrm{SOH}_{\text {can }}$ with $\mathrm{SOH}$ model output.

The measured capacity loss appears to be accelerating while the BMS estimates the opposite trend of less added degradation. Fig. 12 compares $S O H_{\text {meas }}$ vs. $S O H_{\text {can }}$ and clearly visualise that the BMS increasingly overestimates the $\mathrm{SOH}$.

\section{E. Incremental Capacity Analysis}

The ICA method as a SOH estimation tool for EVs has been investigated. The ICA method has been applied to the measured pack voltage and current during the full charges used for the capacity measurements. The IC was calculated first

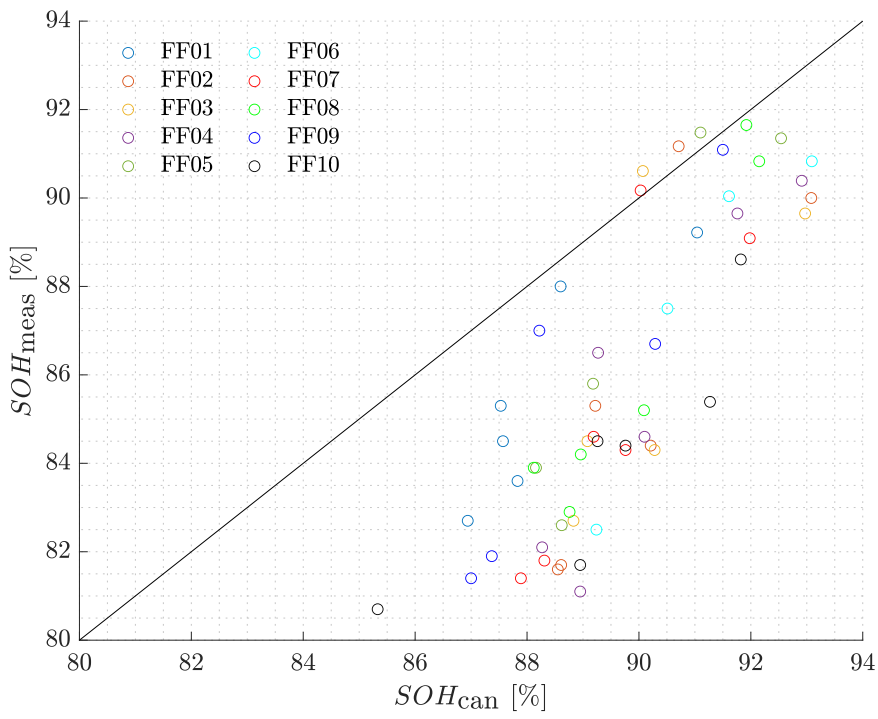

Fig. 12: Comparison of CAN-bus $\mathrm{SOH}$ reading, $S O H_{\text {can }}$, with the $\mathrm{SOH}$ measurement, $S O H_{\text {meas. }}$. The straight line shows the relationship $S O H_{\text {can }} / S O H_{\text {meas }}=1$.

for the base case Nissan e-NV200 Evalia to show the initial peak and valley locations. Two vehicles (FF08 and FF10) were chosen for ICA and the results are shown in Fig. 13b and 13a with the corresponding $\mathrm{SOH}$ measurement shown in the figure label.

There are characteristic peaks and valleys appearing when performing ICA. The peak and valley locations on car level are consistent with the measured $\mathrm{SOH}$. The peaks lowers and moves to the right when the ICA is done for the older battery measured to have a lower capacity. For FF08 the ICA of the last three charges are very similar corresponding to the small difference in the result of the capacity test. It is an advantage of the ICA method that the EV does not have to be completely discharged as there are no valleys or peaks below $350 \mathrm{~V}$.

\section{F. Economic Cost of Degradation}

There is an associated cost of the battery degradation as part of the energy capacity is lost. Assuming a battery cost of 180 $€ / \mathrm{kWh}$ [38], a $24 \mathrm{kWh} \mathrm{EV}$ would cost $€ 4320$. According to the simulation result, there is a $1 \%$ capacity loss per year due to the added energy throughput. This is related to the minimum SOH of $50 \%$ of a second life application, where the battery has lost all value, thus the yearly cost of battery degradation due to FCR-N provision is found to be $€ 86$. This should be compared with the FCR-N capacity payment of $€ 1100$ per year and the cost of conversion losses. The average electricity price for mid-sized industrial customers in Denmark is 0.08 $€ / \mathrm{kWh}$, so the $3.3 \mathrm{MWh}$ of conversion losses per year results in an electricity cost of $€ 263$. The FCR-N provision results in a profit of $1100-263-86=€ 751$. This is however not including the investment and maintenance cost.

\section{CONCLUSION}

An empirical method to measure the battery capacity of electric vehicles $(\mathrm{EV})$ without violating the warranty of the 


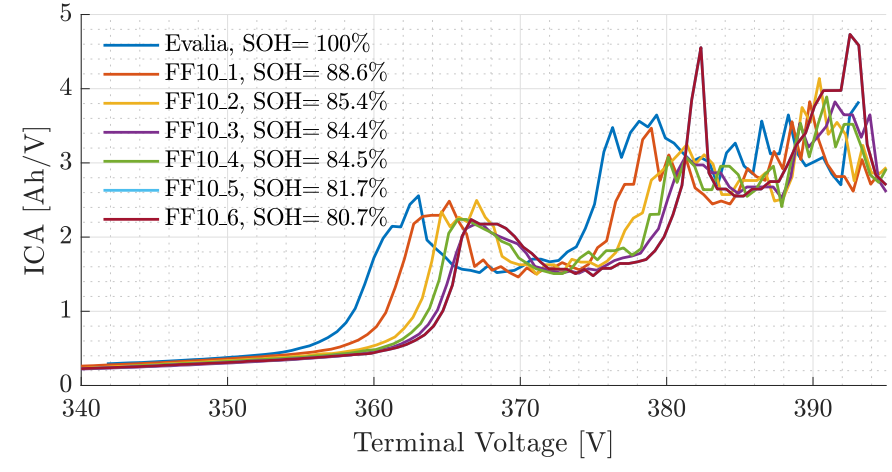

(a) ICA of Evalia and FF10.

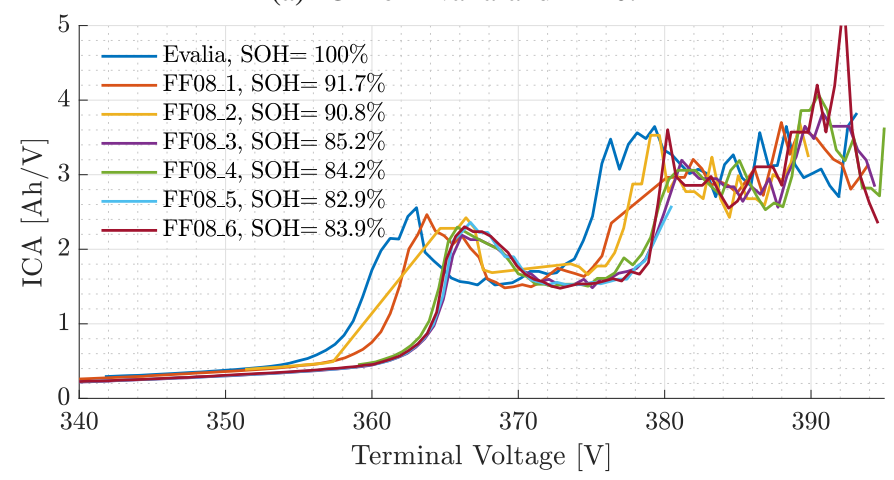

(b) ICA of Evalia and FF08.

Fig. 13: Incremental Capacity vs. terminal voltage during the constant current phase of the Nissan e-NV200 Evalia and two FF EVs for each test round. The $\mathrm{SOH}$ shown in the legend is the results of the charge capacity measurement.

battery is presented. The method requires a DC charger and equipment to measure the voltage and current flow from the charger to the EV and the low voltage consumption at the auxiliary $12 \mathrm{~V}$ battery. The method is used to give a unique empirical insight into what $\mathrm{V} 2 \mathrm{G}$ can do to batteries performing an energy demanding form of grid service. This is done by measuring the capacity of a fleet of ten EVs that on average delivers frequency-controlled normal operation reserve for 15 hours per day, and has a daily measured energy throughput of $50.6 \mathrm{kWh}$.

The battery capacity of the ten EVs is measured six times over a period of three years, the last three years of the five years of service operation. The usable battery capacity was initially $23 \mathrm{kWh}$ : after two years on average is reduced to 20.7 and after five years is reduced to $18.9 \mathrm{kWh}$. The separation of the capacity fade caused by the significant energy throughput due to $\mathrm{V} 2 \mathrm{G}$ service provision from the unavoidable part caused by the battery ageing is provided from the simulation of a industrial battery model. The measured capacity is compared with the results of the model, which predicts a similar degradation, but assigns two thirds of the capacity loss to the ageing and one third to cycling. The simulated $\mathrm{SOH}$ is, after five years of $\mathrm{V} 2 \mathrm{G}$ services, predicted to decrease to $84.3 \%$, which corresponds to a remaining usable capacity of $19.4 \mathrm{kWh}$.

As part of the investigation, the proposed method has been discussed with reference to the ICA method. The ICA was applied on the pack voltage and current during full charges. Characteristic peaks and valleys corresponding to the measured $\mathrm{SOH}$ are appearing when performing ICA. The results obtained in this paper strongly indicates that the ICA method can be applied on car level for EV battery pack $\mathrm{SOH}$ estimation, but only when having real capacity measurements of EVs with similar degradation as a reference.

Future work involves measuring the battery capacity of other $24 \mathrm{kWh}$ Nissan e-NV200 EVs with the same age that have not delivered frequency regulation, to validate the impact of the increased energy throughput. The method is validated with repeated tests on new and old Nissan e-NV200 as presented here. Validation with Nissan LEAF EVs $(24,30,40,62 \mathrm{kWh})$ has been conducted and will be presented in future work of the authors. Additional work should include the validation of the method on EVs from other brands.

\section{REFERENCES}

[1] A. González-Garrido, A. Thingvad, H. Gaztañaga, and M. Marinelli, "Full-scale electric vehicles penetration in the danish island of bornholm-optimal scheduling and battery degradation under driving constraints," Journal of Energy Storage, vol. 23, pp. $381-391,2019$

[2] S. Faddel and O. A. Mohammed, "Automated distributed electric vehicle controller for residential demand side management," IEEE Transactions on Industry Applications, vol. 55, no. 1, pp. 16-25, 2019.

[3] Energinet, "Ancillary services to be delivered in denmark tender conditions," https: //en.energinet.dk/Electricity/Rules-and-Regulations Valid from 15 October 2019.

[4] A. Thingvad, S. Martinenas, P. Andersen, M. Marinelli, B. Christensen, and O. Olesen, "Economic comparison of electric vehicles performing unidirectional and bidirectional frequency control in denmark with practical validation," in 2016 Proceedings of the 51st International Universities Power Engineering Conference. Coimbra, Portugal: IEEE, 2016.

[5] A. Thingvad, C. Ziras, and M. Marinelli, "Economic value of electric vehicle reserve provision in the nordic countries under driving requirements and charger losses," Journal of Energy Storage, vol. 21, pp. 826-834, 2019.

[6] A. Thingvad, C. Ziras, J. Hu, and M. Marinelli, "Assessing the energy content of system frequency and electric vehicle charging efficiency for ancillary service provision," in Proceedings of the 52nd International Universities' Power Engineering Conference. Crete, Greece: IEEE, 2017.

[7] J. D. Bishop, C. J. Axon, D. Bonilla, M. Tran, D. Banister, and M. D. McCulloch, "Evaluating the impact of $\mathrm{v} 2 \mathrm{~g}$ services on the degradation of batteries in phev and ev," Applied Energy, vol. 111, pp. 206-218, 2013.

[8] H. E. Perez, X. Hu, S. Dey, and S. J. Moura, "Optimal charging of li-ion batteries with coupled electro-thermal-aging dynamics," IEEE Transactions on Vehicular Technology, vol. 66, no. 9, pp. 7761-7770, 2017.

[9] X. Li, Q. Wang, Y. Yang, and J. Kang, "Correlation between capacity loss and measurable parameters of lithium-ion batteries," International Journal of Electrical Power and Energy Systems, vol. 110, pp. 819-826, 2019.

[10] M. Thingvad, L. Calearo, A. Thingvad, and M. Marinelli, "Characterization of nmc lithium-ion battery degradation for improved online state estimation," in Proceedings of the 55th International Universities Power Engineering Conference. Torino, Italy: IEEE, 2020.

[11] D. Liu, Y. Song, L. Li, H. Liao, and Y. Peng, "On-line life cycle health assessment for lithium-ion battery in electric vehicles," Journal of Cleaner Production, vol. 199 , pp. $1050-1065,2018$

[12] B. Gou, Y. Xu, and X. Feng, "State-of-health estimation and remaining-useful-life prediction for lithium-ion battery using a hybrid data-driven method," IEEE Transactions on Vehicular Technology, vol. 69, no. 10, pp. 10854-10 867, 2020.

[13] M. Berecibar, I. Gandiaga, I. Villarreal, N. Omar, J. Van Mierlo, and P. Van den Bossche, "Critical review of state of health estimation methods of li-ion batteries for real applications," Renewable and Sustainable Energy Reviews, vol. 56, pp. 572 $-587,2016$

[14] D. Stroe and E. Schaltz, "Lithium-ion battery state-of-health estimation using the incremental capacity analysis technique," IEEE Transactions on Industry Applications, vol. 56, no. 1, pp. 678-685, 2020.

[15] X. Gong, "Modeling of lithium-ion battery considering temperature and aging uncertainties," PhD Thesis, University of Michigan-Dearborn, 2016. [Online]. Available: https://deepblue.lib.umich.edu/handle/2027.42/134041

[16] E. Schaltz, D.-I. Stroe, K. Nørregaard, L. Stenhøj Kofod, and A. Christensen, "Incremental capacity analysis for electric vehicle battery state-of-health estimation," in Proceedings of 2019 Fourteenth International Conference on Ecological Vehicles and Renewable Energies (EVER). Monaco, Monaco: IEEE, 2019.

[17] A. W. Thompson, "Economic implications of lithium ion battery degradation for vehicle-to-grid (v2x) services," Journal of Power Sources, vol. 396, pp. 691 - 709 , 2018.

[18] E. Schaltz, D.-I. Stroe, K. Nørregaard, L. S. Ingvardsen, and A. Christensen, "Incremental capacity analysis applied on electric vehicles for battery 
state-of-health estimation," IEEE Transactions on Industry Applications, vol. 57, no. 2, pp. 1810-1817, 2021.

[19] C. Vidal, O. Gross, R. Gu, P. Kollmeyer, and A. Emadi, "xev li-ion battery low-temperature effects-review," IEEE Transactions on Vehicular Technology, vol. 68 , no. 5 , pp. $4560-4572,2019$.

[20] L. Calearo, A. Thingvad, and M. Marinelli, "Validation of a lumped battery model for electric vehicle degradation studies," (Under Review), 2021.

[21] A. Bartlett, J. Marcicki, S. Onori, G. Rizzoni, X. G. Yang, and T. Miller, "Electrochemical model-based state of charge and capacity estimation for a composite electrode lithium-ion battery," IEEE Transactions on Control Systems Technology, vol. 24, no. 2, pp. 384-399, 2016.

[22] M. Ecker, N. Nieto, S. Käbitz, J. Schmalstieg, H. Blanke, A. Warnecke, and D. U. Sauer, "Calendar and cycle life study of li(nimnco)o2-based 18650 lithium-ion batteries," Journal of Power Sources, vol. 248, pp. 839 - 851, 2014

[23] D. Li, D. L. Danilov, J. Xie, L. Raijmakers, L. Gao, Y. Yang, and P. H. Notten, "Degradation Mechanisms of C6/LiFePO4Batteries: Experimental Analyses of Calendar Aging," Electrochimica Acta, vol. 190, pp. 1124-1133, 2016.

[24] P. Keil, S. Schuster, J. Wilhelm, J. Travi, A. Hauser, R. C. Karl, and A. Jossen, "Calendar aging of lithium-ion batteries: I. impact of the graphite anode on capacity fade," Journal of The Electrochemical Society, vol. 163, pp. A1872-A1880, 01 2016.

[25] M. Corno and G. Pozzato, "Active adaptive battery aging management for electric vehicles," IEEE Transactions on Vehicular Technology, vol. 69, no. 1, pp. 258-269, 2020.

[26] K. Uddin, T. Jackson, W. D. Widanage, G. Chouchelamane, P. A. Jennings, and J. Marco, "On the possibility of extending the lifetime of lithium-ion batteries through optimal v2g facilitated by an integrated vehicle and smart-grid system," Energy, vol. 133, pp. 710 - 722, 2017.

[27] J. Wang, J. Purewal, P. Liu, J. Hicks-Garner, S. Soukazian, E. Sherman, A. Sorenson, L. Vu, H. Tataria, and M. W. Verbrugge, "Degradation of lithium ion batteries employing graphite negatives and nickel-cobalt-manganese oxide + spine manganese oxide positives: Part 1, aging mechanisms and life estimation," Journal of Power Sources, vol. 269, pp. 937 - 948, 2014.

[28] E. Martinez-Laserna, E. Sarasketa-Zabala, I. Villarreal Sarria, D. Stroe, M. Swierczynski, A. Warnecke, J. Timmermans, S. Goutam, N. Omar, and P. Rodriguez, "Technical viability of battery second life: A study from the ageing perspective," IEEE Transactions on Industry Applications, vol. 54, no. 3, pp. 2703-2713, 2018.

[29] A. Thingvad and M. Marinelli, "Influence of v2g frequency services and driving on electric vehicles battery degradation in the nordic countries," in EVS31, 2018.

[30] L. Calearo, A. Thingvad, and M. Marinelli, "Modeling of battery electric vehicles for degradation studies," in Proceedings of the 54th International Universities Power Engineering Conference. IEEE, 2019.

[31] D. Wang, J. Coignard, T. Zeng, C. Zhang, and S. Saxena, "Quantifying electric vehicle battery degradation from driving vs. vehicle-to-grid services," Journal of Power Sources, vol. 332, pp. 193-203, 2016. [Online]. Available: http://dx.doi.org/10.1016/j.jpowsour.2016.09.116

[32] D. Linden, Lindens handbook of batteries. McGraw-Hill, 2008.

[33] J. Pollock, "Leaf spy pro," 2018. [Online]. Available: http://www. electricvehiclewiki.com/wiki/leaf-spy-pro/

[34] A. Kieldsen, A. Thingvad, S. Martinenas, and T. Sørensen, "Efficiency test method for electric vehicle chargers," in Proceedings of EVS29 - International Battery, Hybrid and Fuel Cell Electric Vehicle Symposium, Montreal, Canada, 2016.

[35] D. E. PowerlabDK, "Parker project webpage," http://parker-project.com/ 2016.

[36] P. B. Andersen, T. Sousa, A. Thingvad, L. S. Berthou, and M. Kulahci, "Added Value of Individual Flexibility Profiles of Electric Vehicle Users For Ancillary Services," in IEEE International Conference on Communications, Control, and Computing Technologies for Smart Grids, Aalborg, 2018.

[37] L. S. Berthou, "Flexibility profiling for ev users," Master Thesis in Electrical Engineering, DTU, 2018.

[38] L. Calearo and M. Marinelli, "Profitability of Frequency Regulation by Electric Vehicles in Denmark and Japan Considering Battery Degradation Costs," World Electric Vehicle Journal, vol. 11, no. 3, p. 48, 2020.

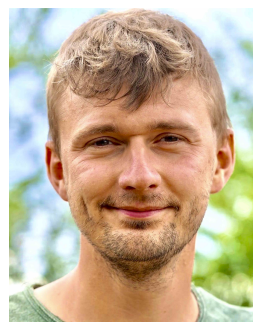

Andreas Thingvad (StM'18) Was born in Skive, Denmark, in 1992. He received the B.Eng. and M.Sc. degrees in electrical engineering from the Technical University of Denmark (DTU), in 2015 and 2017, respectively. Since 2018, he has been working towards a Ph.D. at the Center for Electrical Power and Energy, DTU.

His research focus on electric vehicle grid integration, including determining the need for public charging infrastructure, investigation of the impact on the distribution grid, optimal scheduling

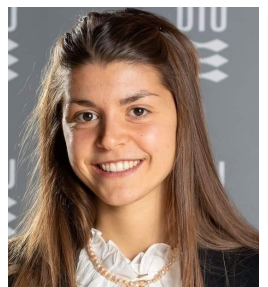

Lisa Calearo (StM'19) was born in Vicenza, Italy, in 1993. She received the B.Sc. degree in Energy Engineering from the University of Padua, Italy, in 2015. She received the Double M.Sc. Degree in Electrical Engineering from the University of Padua and in sustainable energy from the Technical University of Denmark (DTU) in 2018, under the Top Industrial Manager for Europe (T.I.M.E.) collaboration agreement. Currently working as $\mathrm{PhD}$ student at DTU, her research interests include electric vehicles power system integration and grid service support, battery degradation, distribution grid modeling, simulation and testing.

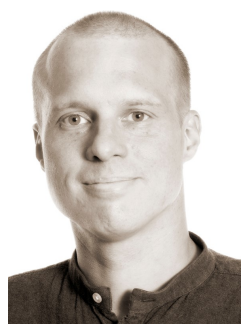

Peter Bach Andersen, (StM'10-M'14) PhD, works as senior scientific researcher at the Center for Electric Power and Energy, part of the Technical University of Denmark (DTU). His main area of research is on how grid integrated electric vehicles may support a stable, economic power system based on renewable energy. Peter has acted as principle investigator in a number of Danish research and demonstration projects. He is also a board member of the Danish EV Alliance (Trade organization) and the advisory board of Copenhagen electric (The Capital Region of Denmark) as to support national R\&D efforts in this area.

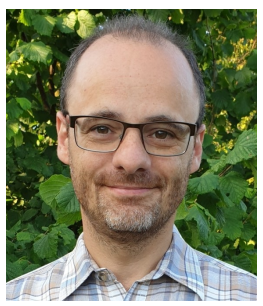

Mattia Marinelli (M'10-SM'17) was born in Genoa, Italy, in March 1983. He received the B.Sc. and M.Sc. degrees in electrical engineering and the European Ph.D. degree in power systems from the University of Genoa, Italy, in 2005, 2007, and 2011, respectively.

Since September 2012, he has been with the Technical University of Denmark (DTU), Roskilde, Denmark, where he is currently an associate professor in distributed energy resources driven electric power systems. His research interests include power system integration studies, wind and solar data analysis, demand-side and electric vehicles management, and distributed energy resources modeling.

Mattia has served as vice-chair and then chair for the PES chapter of the IEEE Denmark Section between 2015 and 2020. 